\title{
Sustainable Energy Alternatives Experimentation at SCT
}

\author{
Javeed Ahmed Khan and Ramani Ranjan Panda \\ Faculty in Power Engineering Department, Electrical and Electronics Section, Salalah College of Technology, P.O. Box No. 608, \\ Salalah 211, Oman
}

Correspondence should be addressed to Javeed Ahmed Khan, vu3jak@rediffmail.com

Received 12 May 2012; Accepted 20 June 2012

Academic Editors: F. Findik and J.-I. Jang

Copyright ( $) 2012$ J. A. Khan and R. R. Panda. This is an open access article distributed under the Creative Commons Attribution License, which permits unrestricted use, distribution, and reproduction in any medium, provided the original work is properly cited.

\begin{abstract}
Sustained energy generation is very important for any region's economic growth either developed or developing. As the growth of the country depends on sustainable and efficient power generation management, in order to attain the sustainable energy generation, experimentation, and explorations in the latest avenues for these generations have to be carried out. In this paper an attempt is made to report the experimentation carried out at Salalah College of Technology (SCT) in terms of sustainable energy generation using alternate energy resources. Experimentation carried out at SCT for solar harnessing in sustainable transportation and wind energy alternatives for hybrid power generation at decentralized levels is tested. Experimentation results for individual experiments are not disclosed. Whereas the overall efficiency in using such alternate technologies for sustained power generation and comparisons with other likewise locations are reported in this paper.
\end{abstract}

\section{Introduction}

Electrical power forms the base line for any economic growth and sustainability in terms of growth factor. It continues to include as one of the secondary basic elements for human growth and sustainability, it also affects the current living standard. Dependency on alternate energy sources will reduce the geopolitical dependency on conventional fuels and enhance the energy security, limit the environmental implications of fossil fuels, and further control the oil price fluctuations $[1,2]$.

At the Power Engineering Department of SCT experimentation on solar energy alternative and wind energy alternatives were carried out in terms of feasibility in transportation concerning with solar energy and electrical power generation with wind energy furthering to storage and/or synchronization to grid in order to improvise the pilot load of the load graph of Salalah region (as it is a standalone region without centralized grid connectivity as of now). Load Forecasting for the region will be buffered with these additional alternate power generating technologies. Experimentation for solar powered electric car is shown in Figures 1 and 2. Vertical axis wind turbine experimentation for power generation is shown in Figures 3 and 4 .
The modern day technology advancements in terms of electrical engineering can be incorporated for better performance and efficiency, in particular advancements in the field of power electronics for efficient conversion from AC to DC and vice versa. Energy efficient motors, better designing by using computer aided design, and so forth, will increase the profitability of energy alternatives applications in many diverse fields.

Students spear headed the willingness in learning the latest technological advancements in electrical engineering for applications in their projects on renewable alternatives, they are duly acknowledged in the acknowledgment section. The actual results obtained are not discussed as the two projects are vast in process and explanation. However the business intelligence in adopting such technologies is discussed in the paper and the avenues present for such methodologies and the future pertaining to such breakthroughs in this region are also discussed.

\section{Business Intelligence for Energy Alternatives}

Perspectives of good business management states profitable returns for investments made in businesses. In order to 


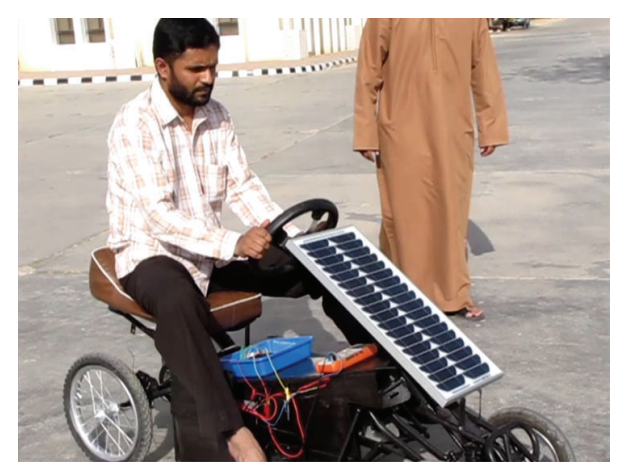

FIGURE 1: Solar-powered electric car experimental setup.

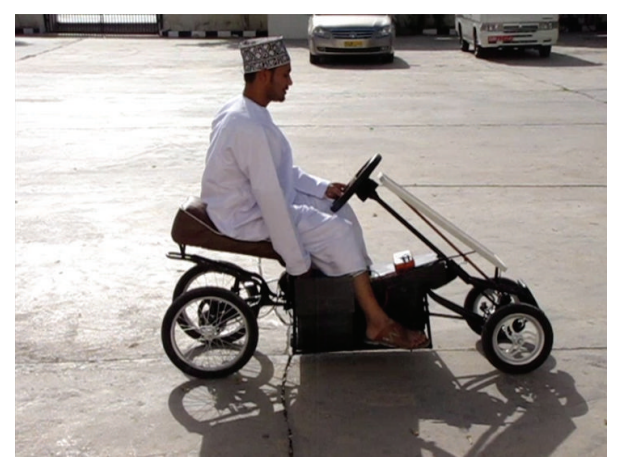

FIgURE 2: Transportation using Solar-powered electric car.

achieve this objective, intelligence gathering of the business is very essential [3]. Business intelligence for energy alternatives quotes responses in solar power harnessing and wind power usages primarily due to its vast and abundant availability as compared to other renewable resources like geothermal or tidal energy on explicit base of abundance and vastness [4].

Figures 5, 6, 7 and 8 show the different graphs for efficient wind power harnessing and are referred from an article in the Electropaedia [5] these data on wind harnessing can be inferred to the present location of Salalah and its nearby regions for hybrid installations of vertical axis wind turbines as developed at SCT. From Figure 5, we can also infer the fact that as the elevation decreases with reference to sea level the wind energy increases. Salalah region is a costal belt hence the wind energy quotient is very high and can be harnessed in conjunction with existing grid as hybrid power for uninterrupted power supply.

Figure 9 shows the actual block diagram of the vertical axis Wind turbine developed at SCT. Guidelines in designing such model were inspired from article no. 6. The converter and inverter design, voltage regulator, DC Control unit, and synchronization to the grid in not discussed in this paper. However, the location comparison for different places and heights is shown in Table 1 referred from articles $[4,6]$.

From Table 1, Average wind speed at different locations near Salalah. We can compare the different heights and the wind speed at different locations height wise. Energy alternative incentives can also be awarded for different levels of utilization [7].

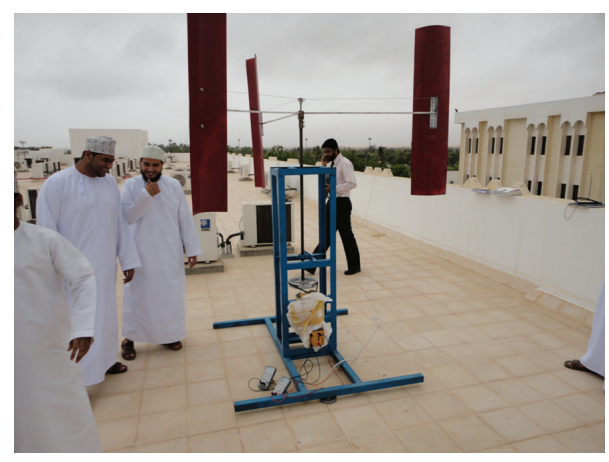

Figure 3: Vertical axis wind turbine setup at SCT.

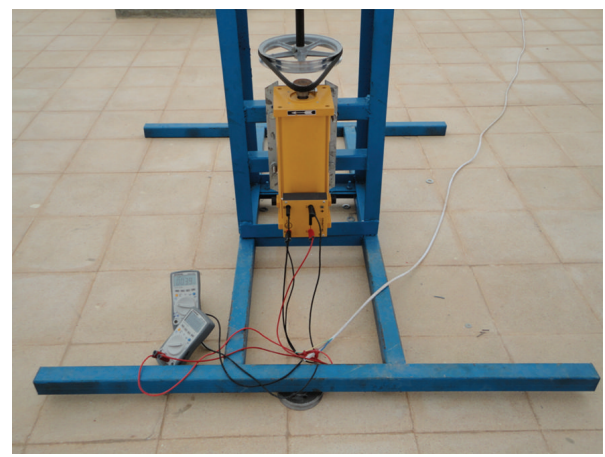

FIGURE 4: Vertical axis wind turbine with DC Generator setup at SCT.

\section{Discussion}

Depending on the proactive initiatives taken up by the government as listed in the official website of Authority for Electricity Regulation in Oman (views expressed by consultants COWI and Partner LLC) in terms of renewable energy resource effective utilization for remote/decentralized locations, it is evident from the findings at sct that it accumulates the electrical engineering fraternity in serving the main objective of green economic development. Solar power harnessing data was not explicitly available for comparison on the present location and for practical purposes the global values of solar insolation was used to calculate the value for the present location [8]. The efficiency obtained in conversion from solar energy to direct electrical energy was very low due to the overall performance of the solar cell assembly (solar panel) used in the study (technical details of the solar panel is $21.6 \mathrm{~V}$ maximum voltage with $1.8 \mathrm{~A}$ short circuit current). The stand-alone weight of solar powered electric car with control circuit and two numbers of $12 \mathrm{~V}$, $9 \mathrm{~A} \mathrm{~h}$ batteries was 35 Kilograms. Its maximum delivered weight was experimented to 83 Kilograms.

\section{Conclusions}

From the results obtained at SCT and the discussion present in this paper, we can conclude that proper data analysis tools available in engineering fraternity, if used along with tactful 
TABLe 1: Average wind speed at different locations near Salalah.

\begin{tabular}{lcccc}
\hline Sl. No. & Place near Salalah & $\begin{array}{c}\text { Average wind speed } \\
(10 \mathrm{~m} \text { above ground level }) \\
\text { in } \mathrm{m} / \mathrm{s}^{2}\end{array}$ & $\begin{array}{c}\text { Average wind speed } \\
(50 \mathrm{~m} \text { above ground level }) \\
\text { in } \mathrm{m} / \mathrm{s}^{2}\end{array}$ & $\begin{array}{c}\text { Average wind speed } \\
(80 \mathrm{~m} \text { above ground level }) \\
\text { in } \mathrm{m} / \mathrm{s}^{2}\end{array}$ \\
\hline 1 & 5.15 & 6.6 & 7.1 \\
2 & Sur & 5.15 & 6.6 & 7.1 \\
3 & Joba & 5.77 & 7.4 & 7.9 \\
4 & Masirah & 5.77 & 7.4 & 7.9 \\
5 & Thumrait & 6.19 & 7.9 & 8.5 \\
\hline
\end{tabular}

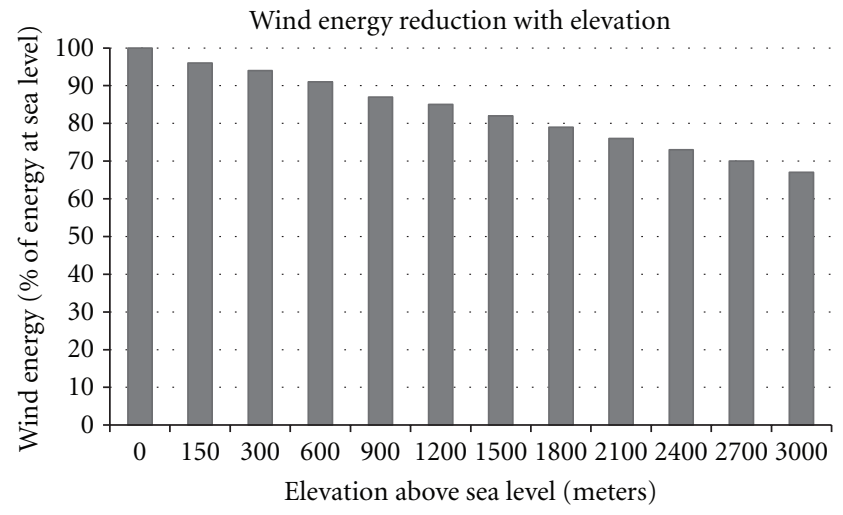

Figure 5: Graph of elevation versus wind energy.

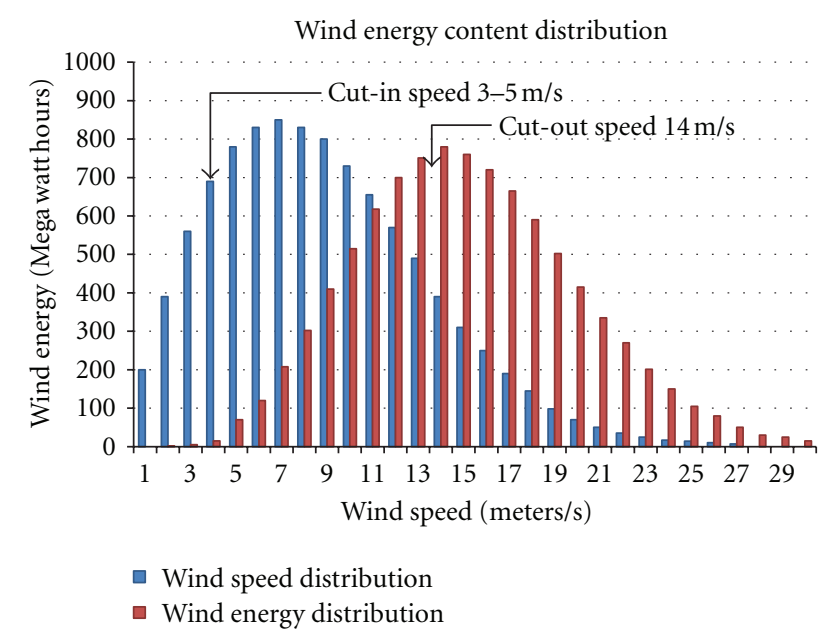

FIGURE 6: Graph of wind speed versus wind energy.

business laws, can achieve maximum utilization of electrical energy alternatives for sustainable growth, hence, resulting in profitability. As the example of solar power harnessing and wind energy usage for electrical power generation in hybrid with BI for optimal locations in Salalah has given maximum profit predictions.

\section{Acknowledgments}

The authors of this paper duly acknowledge the student community of SCT, namely, Group 1 (Solar Powered Electric

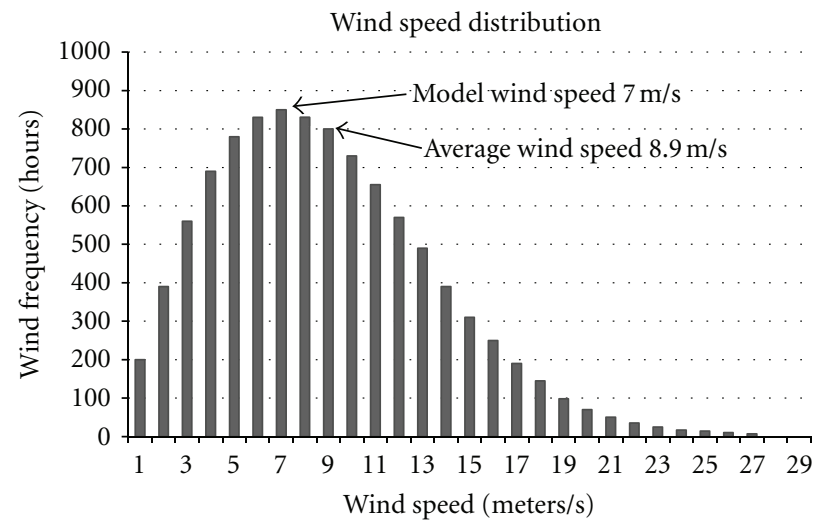

FIGURE 7: Graph of wind speed versus wind frequency.

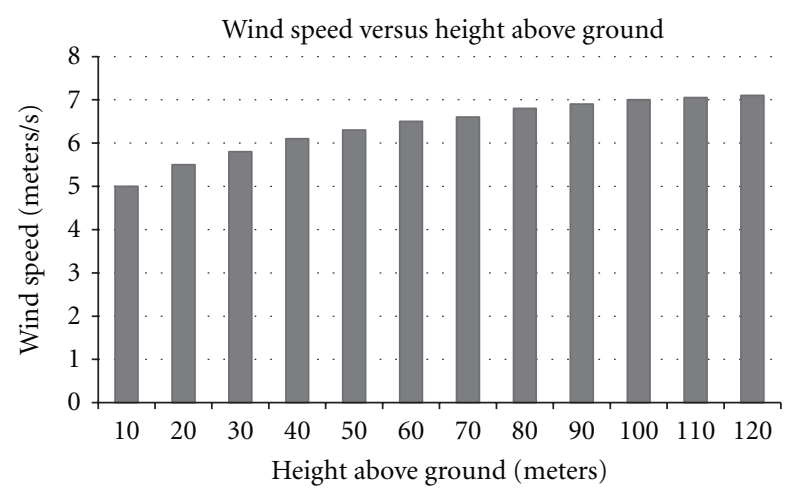

FIGURE 8: Graph of height above ground versus wind speed.

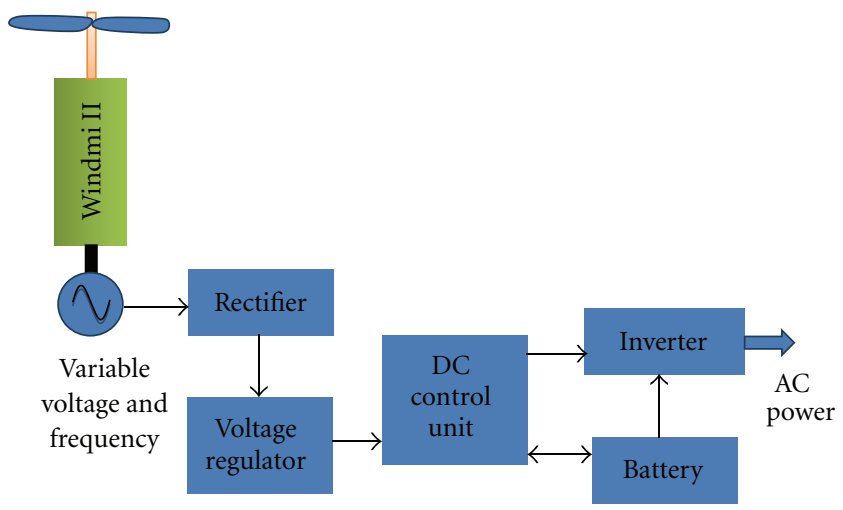

Figure 9: Block diagram representation of vertical axis wind turbine. 
Car-supervised by Dr. Javeed Ahmed Khan): (a) Sami Mohammed Maqbool, (b) Salim Ahmed Al-Yafai; Group 2 (Vertical Axis Wind Turbine-supervised by Dr. Javeed Ahmed Khan and Engineer Ramani Ranjan Panda): (a) Jaber Mubarak Al-Ghafri, (b) Salam Bati Al-Ghafri, (c) Mubarak Abdullah Al-Yaqoobi, (d) Omar Abdullah Al-Abri, and (e) Ali Said Al-Kalbani. Authors place an acknowledgment on record to the Dean (Dr. Ammar Al-Ojaili), Assistant Dean for academics and the teaching fraternity of SCT for their timely help in realizing these two projects.

\section{References}

[1] A. Gastli, Y. Charabi, and S. Al-Yahyai, "Wind energy potential locations in Oman using data from existing weather stations," Research Report, SQU, Muscat, Oman, 2010.

[2] A. H. Al-Badi, A. Malik, and A. Gastli, "Assessment of renewable energy resources potential in Oman and identification of barrier to their significant utilization," Renewable and Sustainable Energy Reviews, vol. 13, no. 9, pp. 2734-2739, 2009.

[3] W. Sullivan, E. Wcks, and J. Luxhoj, Engineering Economy, Prentice Hall, Upper Saddle River, NJ, USA, 2006.

[4] Authority for Electricity Regulation, "Oman study on renewable energy resources," Final Report, 2008.

[5] http://www.mpoweruk.com/wind_power.htm.

[6] A. S. S. Dorvlo, "Estimating wind speed distribution," Energy Conversion and Management, vol. 43, no. 17, pp. 2311-2318, 2002.

[7] M. H. Albadi and E. F. El-Saadany, "The role of taxation policy and incentives in wind-based distributed generation projects viability: Ontario SOP case study," in Proceedings of the 40th North American Power Symposium (NAPS'08), Calgary, Canada, September 2009.

[8] M. R. Patel, Wind and Solar Power Systems, CRC Press, New York, NY, USA, 1999. 

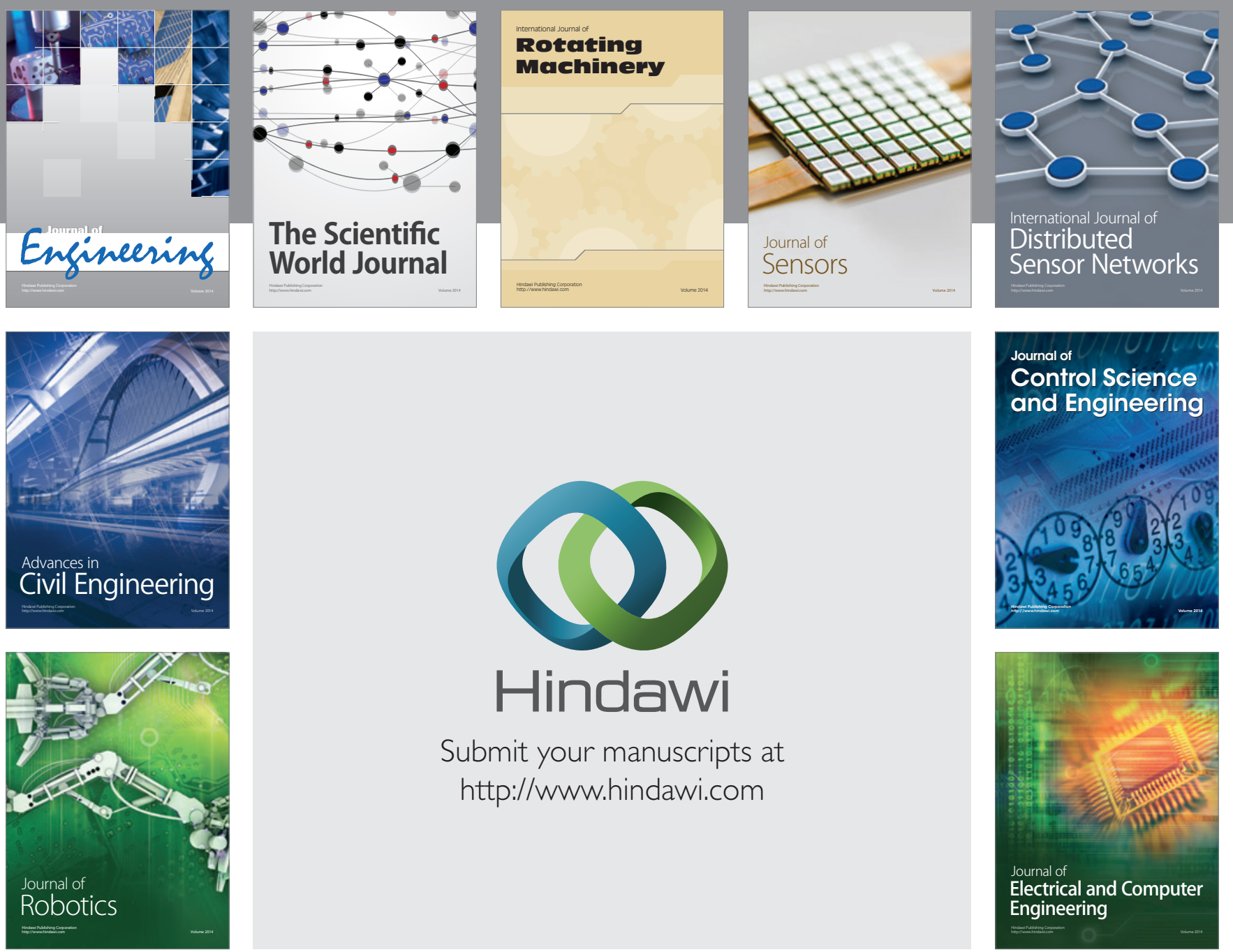

Submit your manuscripts at

http://www.hindawi.com
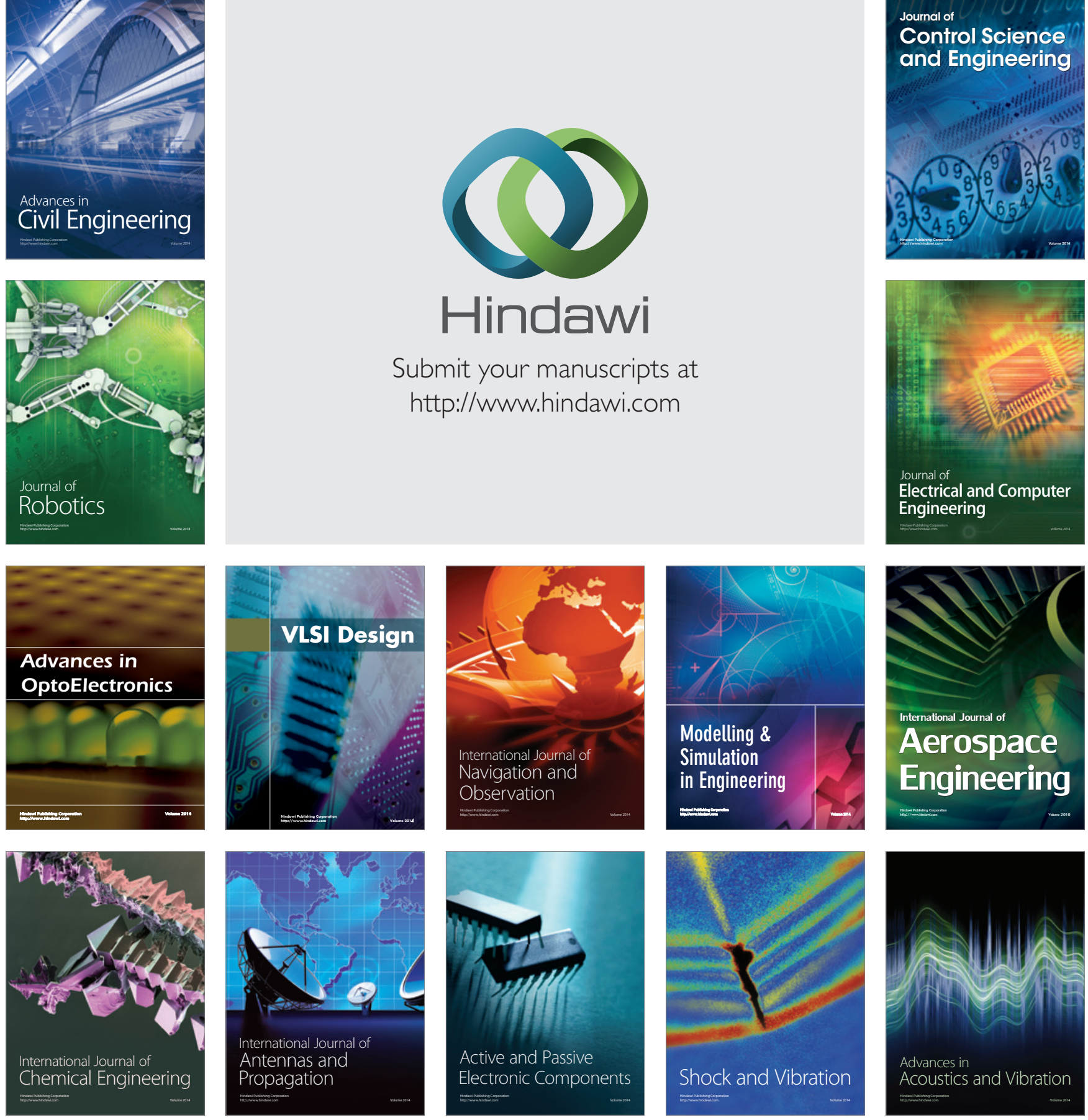